\title{
Soliter ve Dominant Nonfonksiyonel Tiroid Nodüllerinde İntraoperatif Sentinel Lenf Nodunun Bulunması
}

\author{
The Display of Sentinel Lymph Node İntraoperative in Solitary and \\ Dominant Non-Functional Thyroid Nodules
}

\author{
${ }^{1}$ Serkan Sarıkaya, ${ }^{2}$ Feridun Suat Gökçe \\ ${ }^{1}$ Bursa Yüksek İhtisas Eğitim ve Araştırma Hastanesi Genel Cerrahi Kliniği, İstanbul, Türkiye \\ ${ }^{2}$ İstanbul Balıklı Rum Hastanesi Genel Cerrahi Kliniği, İstanbul, Türkiye
}

\begin{abstract}
Özet: Sentinel lenf nodu tiroid nodülünün ilk olarak drene olduğu lenf nodudur. Soliter ve dominant nonfonksiyonel tiroid nodüllerinde intranodüler isosülfan uygulamasının sentinel lenf nodu saptanmasında etkili bir yöntem olup olmadığını saptamayı amaçladık Bu prospektif klinik çalıșma Trakya Üniversitesi Tıp Fakültesi Genel Cerrahi Anabilim Dalı'nda ameliyat edilen soliter ve dominant nonfonksiyonel tiroid nodülü olan, palpabl lenfadenopatisi olmayan 25 olguda yapıldı. İntraoperatif, intranodüler isosülfan mavisi enjeksiyonundan sonra sentinel lenf nodlarının frozen section ve parafin kesit incelemeleri yapıldı ve yöntemin klinik değeri incelendi. Olguların \%48'inde sentinel lenf nodu gösterildi. Lenf nodlarının büyük çoğunluğu tiroiddeki nodülle aynı tarafta ve paratrakeal yerleşimlidir. Tiroid nodülünde malignite saptanan 5 olgunun 4 'ünde sentinel lenf nodu boyandı ve sadece 1 olguda lenfatik metastaz tespit edildi. Sentinel lenf nodları isosülfan mavisi ile boyanan olgularda, lenf nodlarının frozen section ve parafin kesitlerinin sonuçları arasında anlamlı bir fark bulunmadı. Sentinel lenf nodunda frozen section incelemenin tiroid nodülüne oranla sensitivite ve spesifite değerlerinin oldukça yüksek olduğu görüldü.(sensitivite, spesifite \%100). Mikrometastazları ortaya çkarmak için yapılan immunohistokimyasal boyamanın hematoksilen eosin boyamaya bir üstünlüğü olmadığ görüldü. Tiroid nodülü ve sentinel lenf nodu frozen sectıon incelemelerinin birlikte değerlendirilmesi ve malignitenin saptanması cerraha daha küratif bir ameliyat yapma şansı sağlayacaktır. Olgu sayısının ve cerrahi deneyiminin artması, gamma probe eşliğinde lenfosintigrafinin de eklenmesiyle daha yüksek oranla sentinel lenf nodunun gösterilebileceği düşüncesindeyiz.
\end{abstract}

Anahtar Kelimeler: tiroid, tiroid nodülü, sentinel lenf nodu, tiroid kanseri

Abstract: Sentinel lymph node in the first lymph node that thyroid nodule drains. Our aim was to detect if isosulfan injection was effective in detecting solitary and dominant non-functional thyroid nodules. In this prospective study, in 25 cases who were operated inTrakya Univercity medical faculty department of general surgery and who have solitary and non-functional thyroid nodule and who do not have palpable lymphadenopathy, after the intra operative intranodular injection of the isosulfan blue-dye, the frozen section and haematoxylin eosin stained sections investigations of sentinel lymph nodes which were stained together with the thyroid nodule were done and the clinical significance of the method was evaluated. In $48 \%$ of the cases, sentinel lymph node was stained. Most of the lymph nodes were at the ipsilateral side of the nodule in thyroid and located paratracheal. In 4 of the 5 cases, in which malignancy was determined in thyroid nodule, sentinel lymph node was stained and only in one case, lymphatic metastases was indicated.In cases, in which sentinel lymph nodes were stained with the isosulfan blue-dye, there was no significant difference between the frozen section and haematoxylin eosin stained sections results of the lymph nodes. It has been reported that, in proportion to thyroid nodule, in the frozen section investigation, the sensitivity and the spectifity values were very high.(sensitivity, specificity $100 \%$ ). It has been reported that, immunohistochemistry dyeing, which is applied to reveal micrometastases, does not have any superiority than the haematoxylin eosin dyeing. The evaluation of the thyroid nodule investigation together with the sentinel lymph node frozen section investigation and the identification of the malignancy, would provide the chance of a more curative operation for the surgeon. We think that, with an increase in the number of the cases and in the surgical experience, with the including of the lymphoscintigraphy together with the gamma probe, in higher numbers of sentinel lymph nodes can be displayed

Keywords: thyroid, thyroid nodüle, sentinel lymph node, thyroid cancer

ORCID ID of the authors: S.S. 0000-0003-3682-9737; F.S.G. 0000-0001-8597-5787 


\section{Giriş}

Tiroid nodülleri; hem hasta, hem de hekimleri yakından ilgilendiren ve hekimler arasında tanısinda ve tedavisinde zorluklar ve tartışmalar olan bir problem olmaya devam etmektedir (1). Soliter ve dominant tiroid nodüllerinin ele alınması ve tedavisi günümüzün tartışmalı konuları arasında yer almaktadır. Sorunun en önemli bölümü; soliter ve solid olduğu saptanan bir tiroid nodülündeki malignite olasılığının ortaya konulmasidır (2).

Sentinel lenf nodu (SLN), tiroid nodülünün ilk olarak drene olduğu lenf nodülüdür. Tiroid malignitelerinde lenfatik metastazlar, öncelikle bu lenf nodlarında meydana gelir (3). İlk kez 1992 yllinda Morton ve arkadaşları melanomalarda ve daha sonra 1994 yılında Giuliano ve arkadaşları (4) tarafindan meme kanserli hastalarda elektif lenf nodu diseksiyonuna alternatif olarak SLN örneklemesi ve diseksiyonu yapılmıştır. 1998 yılında ise Kelemen ve arkadaşları (5), ilk kez malign tiroid lezyonlarında SLN diseksiyonu gerçekleştirmişlerdir.

Tümörlerde lenf nodu metastazının varlığ evreleme, tedavi seçimi ve prognozu belirleyen en önemli kriterler arasındadır. Nodal metastazların tümü cerrahi olarak tedavi edilmese de birçok tümör tipinde primer tümörle birlikte bölgesel metastazik lenf nodlarının temizlenmesi metastaz/ rekürrens oranlarını düşürür ve sağ kalımı arttırır (2). Ancak her hasta için geniş bölgesel lenf nodu diseksiyonunun sağlayacağ 1 avantaj ile cerrahiye sekonder potansiyel morbidite optimal bir dengede olmalıdır.

$\mathrm{Bu}$ çalışmada, soliter, dominant ve sintigrafik olarak nonfonksiyonel olan tiroid nodüllerinde, ameliyat öncesi klinik muayene, ultrasonografi (USG), ince iğne aspirasyon biyopsisi (IİAB) yapıldıktan sonra intraoperatif, intranodüler isosülfan mavi boya enjeksiyonuyla sentinel lenf nodlarının gösterilmesi ve çıkarılan lenf nodlarının frozen section ve parafin kesitleri sonuçları karşılaştırılmış ve alınan sonuçlara göre bu yöntemin değerlendirilmesinin yapılması amaçland1.

\section{Materyal ve Metodlar}

Prospektif yaptığımız klinik çalışmanın etik kurul onayı alınmıştır (Trakya Üniversitesi Tıp Fakültesi etik kurulu 1203/03). Çalışmaya soliter veya dominant, nonfonksiyonel tiroid nodülü olan 25 olgu alındı. Tüm olgulara ameliyat öncesi dönemde tiroid kan tahlilleri ve tiroid usg yapıldı. Klinik muayene ile tek (soliter) nodülü olan olguların yanında, USG incelemede başka küçük nodüllerin varlığ 1 durumunda büyük nodül dominant nodül kabul edilerek çalışmaya alındı. USG incelemede tamamen kistik nodülü olan olgular çalışmaya alınmadı. Olguların hiçbirinde daha önce boyun bölgesine tedavi amaçlı radyasyon uygulanması anamnezi yoktur. Olguların tamamına poliklinikte İIAB yapıld1.

Tüm olguların ameliyat öncesi indirekt laringoskopla vokal kordları değerlendirildi ve tüm olgulardan onam formu alındı.

Operasyona alınan olgularda Kocher'in kolye insizyonu ile cilt, cilt altı geçildikten sonra orta hat açıldı. Her iki tiroid lobu strap. kaslarının arkasından tekrar palpe edilerek nodülün özellikleri değerlendirildi. Palpasyonda ayrica daha önceden farkedilmeyen başka nodül varlığı araştırıldı. Tiroid venleri ve istmus bağlanmadan önce nodülün merkezine insülin enjektörü ile girilerek $1 \mathrm{ml}, \% 1$ 'lik isosülfan mavisi enjekte edildi. En az 30 sn sonra lenf akımının başladığı görüldü. Nodül içine verilen boyanın lenfatik akımla birlikte venöz drenajının da olduğu saptandı. Pretrakeal, delphian, paratrekeal ve juguler bölge lenfatikleri eksplore edildi.

Tiroid nodülü ve isosülfan mavisi ile boyanan lenf nodlarına peroperatuar frozen section inceleme yapıld1. Frozen section inceleme benign olarak değerlendirilen olgularda ameliyata son verildi. Frozen section inceleme malign ya da malignite açısından şüpheli, ancak kesin karar verebilmek için parafin incelemenin beklenmesi önerilen olgularda diğer tiroid lobu da tiroid kapsülü ile birlikte ekstirpe edilerek bilateral total tiroidektomi uygulandı. İsosülfan mavisiyle boyanan lenf 
nodlarının patolojik incelenmesinde mikrometastazları ortaya çıkarmak amacıyla rutin hemotoksilen eosin boyamanın yanısıra immünohistokimyasal (pankreatin) boyama yapild1.

Çalışmada istatistik metodu olarak ki-kare ve Mc Nemar testleri kullanıldi. $\mathrm{p}<0.05$ anlamlı olarak kabul edildi. Testler TÜTF Dekanlığ Bilgi İşlem Merkezi'ndeki Minitab paket (s0064 minitab release 13)(lisans no:wcp 1331.00197) kullanılarak yapıldı. Preoperatif yapılan tetkiklerden İIAB'nin, ameliyat sırasında çıkarılan tiroid nodülü ve isosülfan mavisi ile boyanan lenf nodlarının frozen incelemelerinin sensitivite, spesifite, pozitif tanımlama oranları ve negatif tanımlama oranları hesaplandı. Çalışmadaki istatistikler Biyoistatistik Anabilim Dalı tarafindan yap1ld.

\section{Bulgular}

Olguların 22'si (\%88 ) kadın, 3'ü (\%12) erkekti. Kadın/erkek oranı $7.3 / 1$ idi. Çalışmaya alınan olguların en genci 26 , en yaşlısı 65 yaşında olup yaş ortalaması $44.2+10.55$ idi. Nodül bulunma bakımından olguların cinsiyete göre farkı olup olmadığı ki-kare testi ile değerlendirildiğinde $p>0.05$ bulundu. İstatistiksel olarak anlamlı bir fark saptanmadi.
Olguların sağlık kuruluşuna başvurmasının en s1k nedeni boyun ön kısmında, tiroid lojunda kitle (\%76), çarpıntı (\%12)ve sıkıntı hissiydi (\%12). Şikayetlerin başlangıcı ile cerrahiye kadar geçen süre minimum 1.5, maksimum 360 , ortalama $55.18+81.44$ ayd 1 .

Ameliyat öncesi dönemde tüm olgularin ötiroid olduğu görüldü. USG bulgusu olarak nodül büyüklüğü en küçük 25 mm, en büyük $50 \mathrm{~mm}$ olup ortalama nodül büyüklüğü olarak saptandı. Olguların hiçbirinde kısa sürede büyüyen, düzensiz, yüzeyli, fikse nodül saptanmadi. Yapilan USG incelemesinde 18 (\%72) olguda nodül solid olarak değerlendirilirken, $7(\% 28)$ olguda nodülün semisolid karakterde olduğu görüldü. USG`de solid olarak değerlendirilen 18 (\%72) olgunun tiroid nodülleri patolojik olarak incelendiğinde 4'ünde (\%16) malignite saptanırken, 14'ü (\%56) benign olarak saptand. Semisolid olarak değerlendirilen 7(\%28) olgunun 1 'inde (\%4) malignite saptanırken, 6'sinda (\%24) benign olarak saptand1. (Tablo 1). USG'de solid veya semisolid olmasına göre maligniteyle aralarında istatistiksel olarak anlamlilik incelendiğinde, ki-kare testine göre anlamlı bir fark bulunmadi $(\mathrm{p}>0.005)$.

Tablo 1.Soliter nodüllerle, dominant nodüllerin patolojik inceleme sonuçları

\begin{tabular}{|lccc}
\multicolumn{1}{c}{ Ultrasonografi } & $\begin{array}{c}\text { Patoloji benign } \\
(\%)\end{array}$ & $\begin{array}{c}\text { Patoloji malign } \\
(\%)\end{array}$ & Toplam (\%) \\
\hline Soliter, solid & $8(\% 32)$ & $3(\% 12)$ & $11(\% 44)$ \\
\hline Soliter, semisolid & $6(\% 24)$ & $1(\% 4)$ & $7(\% 28)$ \\
\hline Dominant nodül & $6(\% 24)$ & $1(\% 4)$ & $7(\% 28)$
\end{tabular}

IIIAB olguların tamamına uyguland. $2(\% 88)$ olgu benign, $2(\% 8)$ olgu şüpheli ve $1(\% 4)$ olgu malign olarak değerlendirildi. İİAB ile benign olarak değerlendirilen 22 olgunun 4'ünde (\%16) kanser saptandi. İIAB'de atipik hücreler görülen ya da şüpheli olarak değerlendirilen 2 (\%8) olgunun parafin incelemelerinde tiroiddeki nodül benign olarak değerlendirildi. İİAB'de şüpheli hücreler görülmesi kanser açısından pozitif kabul edilerek yapılan değerlendirmede, İ̇AB 'nin sensitivitesi $\% 20$, spesitivite $\% 90$, pozitif tanımlama oranı \%33.3, negatif tanımlama oran $1 \% 81.8$ olarak bulundu .

Olgularin preoperatuar frozen section incelemede 24 (\%96) olgu benign, 1 (\%4) olgu malign olarak değerlendirildi. Frozen section incelemede benign olarak değerlendirilen 24 olgunun 4'ünde parafin kesitlerde malignite olacak şekilde toplam 5 olguda malignite saptand1. Frozen section 
inceleme sonuçları, ki-kare testi kullanılarak parafin inceleme sonuçları ile karşılaştırıldığında $\mathrm{p}<0.05$ olarak hesaplandı (Tablo 2). Frozen section ve parafin kesitler arasında istatistiksel olarak anlamlı bir fark bulundu ve çalışmamızda frozen section incelemenin çok güvenli bir yöntem olmadığ 1 saptand. Sensitive $\% 20$, spesifite $\% 100$, pozitif tanımlama oran1 \%100, negatif tanımlama oranı \% 83.3 olarak bulundu. Frozen section incelemesinde benign olan fakat parafin blokta malign tanisı konan 4 olgunun ikisi papiller mikrokarsinom, ikisi ise papiller karsinom olarak saptand. Frozen sectionda malign saptanan olguda papiller karsinomdu.

Tablo 2. Tiroid nodülünün frozen section ve parafin incelem sonuçlarının karşılaştırılması

\begin{tabular}{cccc} 
Frozen Section & $\begin{array}{c}\text { Parafin inceleme } \\
\text { Benign } \\
(\%)\end{array}$ & $\begin{array}{c}\text { Parafin inceleme } \\
\text { Malign }\end{array}$ & $\begin{array}{c}\text { Toplam } \\
(\%)\end{array}$ \\
Benign & $20(\% 80)$ & $(\%)$ & $24(\% 96)$ \\
Malign & 0 & $1(\% 4)$ & $1(\% 4)$ \\
Toplam (\%) & $20(\% 80)$ & $5(\% 20)$ & \\
\hline
\end{tabular}

Olgularımıza yapilan intraoperatif, intranodüler isosülfan mavi boya enjeksiyonundan sonra lenf nodüllerinin görüntülenmesi; minimal 30 saniye, maksimal 5 dakika sonunda, ortalama 97.5+78.22 saniye içinde gerçekleşti. Daha sonra üstte hyoid kemik, altta jugulum, lateralde internal juguler vene kadar olan alanda isosülfan mavisi ile boyanan SLN (tiroiddeki nodülün ilk olarak drene olduğu nodül /nodüller) araştırıldı ve eksize edildi. Çalışma grubunda 25 olgudan 12 'sinde (\%48) isosülfan mavisi ile sentinel lenf nodlarının boyandığı görüldü. İsosülfan mavisi ile boyanan lenf nodları incelendiğinde; 2 olguda yalnızca pretrakeal, 4 olguda paratreakel, 2 olguda delphian lenf nodunun, 1 olguda ise juguler bölgedeki lenf nodunun boyandiğg görüldü.

Tüm olgular birlikte değerlendirildiğinde, tiroid nodülünde parafin kesitlerde malignite saptanan toplam $5(\% 20)$ olgudan 4'ünde (\%16) sentinel lenf nodu / nodlarının isosülfan mavisi ile boyandığı gözlendi. Malignite saptanan 1 olguda boyanma olmadı. Malignite saptanan isosülfan mavisi ile lenf nodu boyanan olgulardan sadece 1'inde lenf nodu metastazı saptand1. SLN boyanan diğer 8 (\%32) olgunun tiroid nodülerinin parafin incelemeleri, benign olarak değerlendirildi. $\mathrm{Bu} 8$ olgunun lenf nodları, frozen section inceleme ve parafin kesirlerdeki incelemelerde benign olarak saptand1.
Lenf nodu isosülfan mavisi ile boyanan 12 olguda, sentinel lenf nodülü ile tiroiddeki nodülün frozen section incelemeleri ki-kare testi ile karşılaştırıldığında $p=1, \quad(p>0.05)$ olarak bulundu ve istatistiksel olarak anlamlı bir fark saptanmadı. Çünkü bu olgu dişında, 11 olgunun frozen section inceleme sonuçları benign idi. Malignite saptanan 1 olgunun hem tiroid nodülü hemde SLN frozen section inceleme sonucu malign idi.

Olguların 8'inde (\%32) tiroiddeki nodül ve isosülfan mavisiyle boyanan nodun benign, 3'ünde (\%12) tiroiddeki nodülün malign olduğu halde, lenf bezi metastazının olmadığı, 1 'inde $(\% 4)$ ise tiroiddeki nodülün malign ve lenfatik metastazının olmadığı saptandı. Lenf nodu isosülfan mavisi ile boyanan 12 olguda, parafın kesit incelemeleri, mikrometastazları ortaya çıkarmak için hematoksilen eosin boyamadan sonra immunohistokimyasal (pankreatin) boyama ile değerlendirildi. Lenf nodu metastaz1 saptanmayan 11 olguda bu boyama ile de metastaz saptanmad. Her iki boyama arasındaki istatistiksel anlamlilik kikare testi ile değerlendirildiğinde $p>0.05$ olarak bulundu ve anlamlılık saptanmadi.

İsosülfan mavisi ile boyanan $12(\% 48)$ olgu değerlendirildiğinde ancak 1 (\%4) olguda lenfatik metastazın olduğu görüldü. Metastaz frozen section ve parafin incelemelerle doğrulandı. Diğer tüm olguların frozen section ve parafin (hematoksilen eosin boyama, 
immonohistokimyasal) incelemeleri reaktif hiperplazi (benign) olarak değerlendirildi. Frozen sectionda tiroid nodülü ve sentinel lenf nodu malign saptanan olguya santral lenf disseksiyonu yapılmıştır. Bu olgu dışındaki diğer olguların hiçbirine santral lenf disseksiyonu yapılmamıştır.

\section{Tartışma}

Tiroid nodülleri oldukça sık görülen bir klinik durum olup erişkin popülasyonun \% 2-7' sinde görülür (3). Herhangi bir nedenle yapılan boyun USG' de erişkinlerin \% 7-21 'inde tiroid nodülü bulunabilir. Tüm tiroid nodüllerinin \% 5-10 ' unda malignite görülür $(3,6)$. Bu nodüllerin çoğu soğuk nodüllerdir (7). Ancak soğuk nodüllerin de \% 75-90 kadarı benigndir $(8,9)$. Bu nedenle malignite riski yüksek olanlar tespit edilerek cerrahi tedavi uygulanmas1, benign olanlarda ise gereksiz cerrahi müdahalelerden kaçınılması gerekir (3).

Tiroid kanserleri tüm kanserlerin \% 1'ini oluşturur (10). Otopsi çalışmalarında tiroid kanser insidans1 ise \% 3,5-35,6 arasinda bulunmuştur (11). Çocuklarda soğuk tiroid nodülünün yetişkinlere göre daha az görüldüğü ama bunlarda malignite oranının yetişkinlerden 2 kat fazla olduğu görülmüştür (3). Bu çalışmada olguların büyük kısmını 4049 yaş grubu (4. dekat) oluşturuyordu.

Çoğu olgu (\%76) literatürdeki gibi boyun ön kısmında kitle şikayeti ile başvurmuştu (3). Şikayetler ortalama 55 ay önce fark edilmişti. Hiçbir olguda kısa sürede büyüyen nodül anamnezi yoktu.

Tiroid nodülleri kadınlarda erkeklere göre 3-8 kez daha sık görülür (12). Çalışmamızda kadın-erkek oranı $7,3 / 1$ ve yaş ortalaması 44,2 olarak literatürle uyumlu bulundu. Ancak literatürde erkeklerdeki nodüllerde malignite oranı daha fazladır (12).

İIAB'nin sensitivitesi \%83-99, spesifitesi \%70-100 seviyelerindedir (3). İİAB'nin benign tiroid nodülü olan hastalarda gereksiz ameliyatları azaltması ve malign olanlarda cerrahi tedavinin tek seansta tamamlanmasıyla, reoperasyon ve buna bağlı olarak ortaya çıkabilen komplikasyonları azaltması en büyük avantajlarıdır (3). İ̇AB şüpheli olan tiroid nodülü nedeniyle ameliyat edilen hastaların \%15-40'ında malignite saptanmıştır. $\mathrm{Bu}$ nedenle IİAB'de şüpheli olarak değerlendirilen tüm nodüllerin cerrahi eksizyonu önerilmektedir (7). Malignite şüphesi olan hastalarda İ̇AB hücresel düzeyde tanıya yardımcı olması nedeniyle çok değerlidir (10). Bu çalışmadaki tüm olgulara USG incelemesi yapıldıktan sonra USG eşliğinde İIAB yapıldı. İIAB'nin sensitivetisi $\% 20$, spesifitesi $\% 90$, pozitif tanımlama oran 1 $\% 33.3$, negatif tanımlama oran $1 \% 81,8$ olarak bulundu.

Medüller tiroid kanserlerinde lenf nodu metastazlarının yüksek oranda olmaları nedeniyle cerrahi tedavi sadece total tiroidektomi ile kalmayıp mutlaka santral lenf nodu diseksiyonu da gerekmektedir (13). Papiller tiroid kanserinde lenf nodu diseksiyonunun gerekli olup olmadığı, eğer yapılacaksa bunun ne çeşit bir diseksiyon olacağı konusunda fikir birliğine varılamamıștır. Ancak tiroiddeki nodülün ilk olarak drene olduğu lenf nodunun çıkarılarak lenfatik metastazın araştırılması ve buna göre diseksiyonun planlanması günümüzün popüler konuları arasında yer alan SLN örneklemesini gündeme getirmiştir (5).

Sentinel lenf nodunun görüntülenmesinde kullanılan boyalar çeşitlilik göstermektedir. Pelizzo ve arkadaşları (14) \%5'lik patent blue violet, Kelemen ve arkadaşları (5) \%1'lik isosülfan mavisi kullanmışlardır. Fukui ve arkadaşları (15), metilen mavisi kullanmışlar ve diğer boyalarla sonuçlar arasında bir fark olmadığını saptamışlar, hatta maliyetin daha düşük olduğunu bildirmişlerdir. Kullanılacak boyanın miktarı ise nodülün büyüklügüne göre değişmekle birlikte $0.25 \mathrm{ml} / \mathrm{cm}$ olarak formüle edilmiştir (14). Bu çalışmada, tiroid malignitelerinde yapılan ilk çalışmada (5) kullanılan \%1'lik isosülfan mavisinden 0.5-1 ml kullanıldı.

İsosülfan mavisinin nodül içine veya nodül etrafina verilip verilmeyeceği konusunda tartışmalar vardır. Yapılan çalışmalarda genel olarak intranodüler enjeksiyon tekniği kullanılmıştır(14). Ancak Fukui ve arkadaşlanı (15), metilen mavisini tümörün etrafina, 4 
kadranda enjekte ederek lenfatik görüntülenmeyi sağlamışlardır. Ancak isosülfan mavisi ve lenfosintigrafinin birlikte kullanıldı̆̆ 1 bir çalışmada tiroidin kanlanmasının ve lenfatik akımının fazla olmasi nedeniyle, nodül etrafına verilen radyoaktif madde ve isosülfan mavisinin, farklı lenf nodlarını gösterdiği ve bu nedenle sentinel lenf nodunun doğru olarak tespit edilmediğini savunmuşlardır (16). Aynı amaçlı yapılan lenfosintigrafik çalışmalarda da Tc-99m-nanocolid intranodüler olara enjekte edilmiştir (17). $\mathrm{Bu}$ çalışmada intranodüler isosülfan mavi boya enjeksiyonu kullanıldi.

İsosülfan mavisinin intranodüler enjeksiyonu sırasında nodül dıșına taşarak çevre dokuları boyamas1 ve yetersiz eksplorasyona neden olmas1 gibi dezavantajlar1 vardır $(5,14)$. İsosülfan mavi boya enjeksiyonundan sonra saniyeler içinde sentinel lenfatik kanallarda akımın başladığ 1 ve en erken 30 saniye, en geç 15 dakika içinde sentinel lenf nodlarının boyandığı görülmüştür. Bu boyanma sırasında sadece üstte hyoid kemik, altta jugulum, lateralde karotis k1lifa kadar olan alan diseke edilmiş, ,ek bir diseksiyona gidilmemiştir $(15,16)$. Sadece mediastinal lenf nodlarının boyandığ 1 durumlarda ise SLN boyanmasının olmadığı sonucuna varılmıștır (5). Bizimde çalışmamızda sentinel lenf nodlarının bu çalışmalara benzer olarak en erken 30 saniye sonra tutulum başladı. Çalışmamızda en geç sentinel lenf nodu tutulumu ise 5.dakika sonunda oldu.

Yapılan çalışmalarda sentinel lenf nodunun; tiroiddeki nodülün üst pol lokalizasyonunda prelaringeal, istmus ve alt anteromedial lokalizasyonunda ise paratrakeal ve juguler bölgede oldukları saptanmıştır (15). Bu çalışmada lokalizasyonlar literatürlerle uyumluydu.

Yapılan çalışmalarda lenfatik metastazların \% 7-22 oranında juguler bölgede olduğu, bunun dışındakilerin tamamının santral bölgede lokalize olduğu saptanmıștır (5). Bu çalıșmada \%8 oranda juguler bölgede SLN tespit edildi. Çalışmalarda isosülfan mavisinin \%65-95.5 oranında sentinel lenf nodlarını görüntülemede başarılı olduğu gösterilmiştir
$(14,15)$. Bu çalışmada \%48 oranında SLN saptand1.

Yapılan çalışmalarda, preoperatif yapılan İIAB ile doğruluğu tam olarak kanıtlanmış malign lezyonlarda yapıldığı için sentinel lenf nodundaki malignite oranının yüksek olduğu görüldü. $\mathrm{Bu}$ çalışmada ise malign potansiyeli olabilecek soliter veya dominant nonfonksiyonel nodüllerin tamamı çalışmaya alındığından sentinel lenf nodundaki malignite oranı düşük bulundu. Preoperatif İ̇AB ve peroperatif frozen section inceleme ile tiroid nodülündeki malignitenin saptanmasındaki zorluklar nedeniyle, sentinel lenf nodundaki malignitenin saptanabilmesinin tanıya katkıs1 olacağı düşüncesindeyiz. Başka bir ifadeyle sentinel lenf nodlarındaki maligniteyi saptarsak, frozen sectiondaki tanının doğruluğunu kanıtlayabiliriz.

Hipoaktif, solid nodülü olan hastalarda malignite tanısı ve yapılacak cerrahi işlemin planlanmasinda, frozen section incelemesi kullanılabilmektedir (7). Ancak günümüzde İIAB, malignitenin preoperatif saptanmasında oldukça yararlı olduğundan frozen section incelemenin sadece İ̈AB ile tanı konulamayan ya da şüpheli olgularda uygulanması olabilir. Bu çalıșmada, tiroiddeki nodülün frozen incelemedeki tanı değerine bakıldığında sensitivite $\% 20$, spesifite $\% 100$, pozitif tanımlama oranı \%100, negatif tanımlama oranı \%83.3 olarak bulundu. Çalışmalarda isosülfan mavisiyle boyanan sentinel lenf nodlarının frozen section incelemesinde \%91-100 oranında tanı konulmuş ve bu sonuçlar parafin sonuçlarıyla doğrulanmıştır $(5,14,15)$. Bu çalışmada lenf nodüllerinin frozen section incelemedeki tanı değerine bakıldığında sensitivite ve spesifite $\% 100$ olarak bulunmuştur. Sentinel lenf nodlarındaki metastazlı olguların sayısı arttıkça bu oranların gerçek değeri ortaya çıkacaktır.

\section{Sonuc}

Soliter veya dominant tiroid nodüllerinde isosülfan mavi boya enjeksiyonuyla $\% 48$ oranında sentinel lenf nodları görüntülendi. Ancak bu olgu sayısının ve deneyimin artırılması, gamma probe eşliğinde 
lenfosintigrafinin de eklenmesiyle daha yüksek oranda sentinel lenf nodunun gösterilebileceği kanısına varıldı

\section{Teşekkür}

Prof. Dr. Mehmet Emin Irfanoğlu hocamıza teşekkür ederiz.

\section{KAYNAKLAR}

1. Xing M, Alzahrani AS, Carson KA, Shong YK, Kim TY, Viola D, et al. Association Between BRAF V600E Mutation and Recurrence of Papillary Thyroid Cancer. $J$ Clin Oncol. 2015;33:42-50.

2. Sever AR, Mills P, Weeks J, Jones SE, Fish D, Jones PA, et al. Preoperative needle biopsy of sentinel lymph nodes using intradermal microbubbles and contrast-enhanced ultrasound in patients with breast cancer. $A m J$ Roentgenol. 2012;199:465-70.

3. Sabel MS, Staren ED, Gianakakis LM, Dwarakanatan S, Prinz RA. Use of fineneedle aspiration biopsy and frozen section in the management of the solitary thyroid nodule.Surgery 1997;122:1201-07.

4. Giuliano AE, Kirgen DM, Guenter JM , Morton DL. Lymphatic mapping and sentinel lymphadenectomy for breast cancer. $A m J$ Surg. 1994;220:391-410.

5. Kelemen PR,Van Herle AJ, Giuliano AE Sentinel Iymphadenectomy in thyroid malignant neoplasms. Arch Surg 1998;133:288-92.

6. Fang W, Ye L, Shen L, Cai J, Huang F, Wei $\mathrm{Q}$, et al. Tumor-associated macrophages promote the metastatic potential of thyroid papillary cancer by releasing CXCL8. Carcinogenesis. 2014;35:1780-1787

7. Patwardhan N, Cataldo $\mathrm{T}$, Braverman LE: Surgical management of the patient with papillary cancer. Surg Clin North Am 1995;75:449-64.

8. Tan Z, Ge MH, Zheng CM, et al. The significance of Delphian lymph node in papillary thyroid cancer. Asia Pac J Clin Oncol. 2017;13:e389-e393.

9. Lee YC, Shin SY, Kwon KH, Eun YG. Incidence and clinical characteristics of prelaryngeal lymph node metastasis in papillary thyroid cancer. Eur Arch Otorhinolaryngol 2013; 270: 2547-50.

10. Liu F, Zhu Y, Qian Y, Zhang J, Zhang Y, Zhang Y. Recognition of sentinel lymph nodes in patients with papillary thyroid cancer by nano-carbon and methylene blue. Pak J Med Sci. 2017;33:1485-89.

11. Morton DL, Thompson JF, Essner R, et al. Validation of the accuracy of intraoperative lymphatic mapping and sentinel lymphadenectomyfor early-stage melanoma: a multicenter trial. Multicenter Selective Lymphadenectomy Trial Group. Ann Surg. 1999;230:453-63; discussion 463-5.
12. Chai YJ, Kim SJ, Choi JY et al. Papillary thyroid carcinoma located in the isthmus or upper third is associated with Delphian lymph node metastasis. World J Surg 2014; 38: 130611.

13. Tian W, Jiang Y, Gao B, et al. Application of nano-carbon in lymph node dissection for thyroid cancer and protection of parathyroid glands. Med Sci Monit. 2014;20:1925-30.

14. Pelizzo MR, Boschin IM, Toniato A, et al. The sentinel node procedure with patent blue $\mathrm{V}$ dye in the surgical treatment of papillarythyroid carcinoma. Acta Otolaryngol 2001;121:421-24.

15. Fukui Y, Yamakawa $\mathrm{T}$, Taniki $\mathrm{T}$, et al. Sentinel lymph node biopsy in patients with papillary thyroid carcinoma. Cancer 2001;92:2868-74.

16. Catarci M, Zaraca F, Angeloni $\mathrm{R}$, et al. Preoparative lymphoscintigraphy and sentinel lymph node biopsy in papillary thyroid cancer. A pilot study. J Surg Oncol 2001;77:21-24.

17. Rettenbacher L, Sungler $P$, Gmeiner D, Kassmann H,Galvan G. Detecting the sentinel lymph node in patients with differentiated thyroid carcinoma. Eur J NUCL Med 2000;27:1399-1401. 